\title{
Epidemiological situation, laboratory capacity and preparedness for carbapenem-resistant Acinetobacter baumannii in Europe, 2019
}

Felix Lötsch ${ }^{1}$, Barbara Albiger ${ }^{1}$, Dominique L. Monnet ${ }^{1}$, Marc J. Struelens ${ }^{1}$, Harald Seifert ${ }^{2,3}$, Anke Kohlenberg ${ }^{1}$, European Antimicrobial Resistance Genes Surveillance Network (EURGen-Net) carbapenem-resistant Acinetobacter baumannii capacity survey group 4

1. European Centre for Disease Prevention and Control (ECDC), Stockholm, Sweden

2. Institute for Medical Microbiology, Immunology and Hygiene, University of Cologne, Cologne, Germany

3. German Center for Infection Research (DZIF), partner site Bonn-Cologne, Germany

4. The EURGen-Net carbapenem-resistant Acinetobacter baumannii capacity survey group members are listed below

Correspondence: Anke Kohlenberg (anke.kohlenberg@ecdc.europa.eu)

Investigators: The members of the EURGen-Net carbapenem-resistant Acinetobacter baumannii capacity survey group are listed at the end of the article.

Citation style for this article:

Lötsch Felix, Albiger Barbara, Monnet Dominique L., Struelens Marc J. , Seifert Harald, Kohlenberg Anke, European Antimicrobial Resistance Genes

Surveillance Network (EURGen-Net) carbapenem-resistant Acinetobacter baumannii capacity survey group. Epidemiological situation, laboratory capacity and

preparedness for carbapenem-resistant Acinetobacter baumannii in Europe, 2019. Euro Surveill. 2020;25(45):pii=2001735. https://doi.org/10.2807/1560-7917.

ES.2020.25.45.2001735

To update information on the epidemiological situation and national capacity for detection, surveillance and containment of carbapenem-resistant Acinetobacter baumannii (CRAb) in Europe, we performed a survey in 37 countries. Nine countries reported regional or inter-regional spread and seven an endemic situation. Laboratories with a reference function, surveillance systems, and a national containment plan for CRAb existed in 30, 23 and eight countries, respectively. A pan-European molecular survey would provide indepth understanding of the CRAb epidemiology.

To better understand the current epidemiological situation of carbapenem-resistant Acinetobacter baumannii (CRAb) in Europe and the surveillance and control activities in invididual countries, we conducted a survey in 37 countries. The main aims were (i) to update the information about the epidemiological stages of spread of CRAb in Europe, and (ii) to assess the current national capacity for laboratory detection, identification and characterisation, surveillance and containment of CRAb.

\section{Terminology}

Most nosocomial outbreaks are caused by $A$. baumannii sensu stricto (s.s.), which is characterised by its ability to survive long periods of time on dry surfaces [1], while outbreaks of other closely related species are rare. In this report and unless specified otherwise, 'A. baumannii', or 'Ab' as in CRAb, refer to A. baumannii s.s. as a species (and not the $A$. calcoaceticus- $A$. baumannii complex or the $A$. baumannii group).

\section{Epidemiological situation}

A questionnaire using the EUSurvey online tool was sent to the EURGen-Net national coordinators from 37 countries in December 2019. The questions in this survey about the situation in 2019 were adapted from two previous assessments of CRAb in Europe, one in 2013 for that same year [2] and one in 2015 covering 2014 and the beginning of 2015. To assess the epidemiological stage of CRAb dissemination across each country, a previously used seven-stage scale (o, 1, 2a, 2b, 3, 4 and 5) was applied [3]. All contacted coordinators completed the survey, with individual answers received from the United Kingdom (UK) for England, Northern Ireland, Scotland and Wales. While the data for these four countries in the UK are shown separately in some of the tables of the current report, all analyses count the United Kingdom as a single country.

With regards to the epidemiological stage of spread in 2019, 10 countries reported sporadic, unrelated cases (stage 1), two reported single hospital outbreaks (stage 2a), eight reported sporadic hospital outbreaks (stage 2 b), five reported regional spread (stage 3), four reported inter-regional spread (stage 4), and seven reported an endemic situation (stage 5). For one country the stage was uncertain. The epidemiological stages by country are shown in the Figure and a comparison with the results from previous similar surveys is provided in Table 1. Compared to the result of the 2015 survey, there was a decrease of the epidemiological stage in 13 countries, an identical stage in 16 countries, and an increase in five countries. No comparison could be made for three countries as no epidemiological stage was available from the 2015 study (Table 1 ). 
Epidemiological situation of carbapenem-resistant Acinetobacter baumannii, assessment by national experts in European countries, $2019(\mathrm{n}=37)$
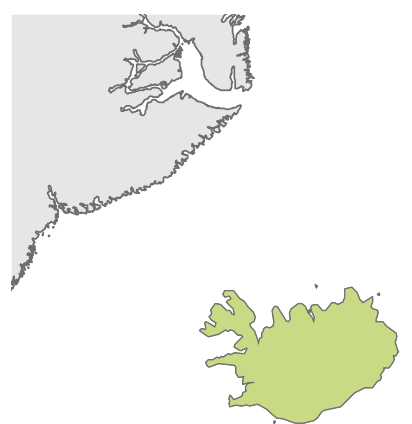

Epidemiological stage

$\square$ Sporadic occurrence

$\square$ Single hospital outbreak

$\square$ Sporadic hospital outbreaks

Regional spread

Inter-regional spread

Endemic situation

Stage uncertain

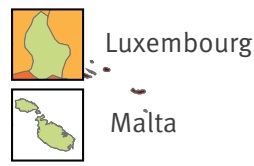

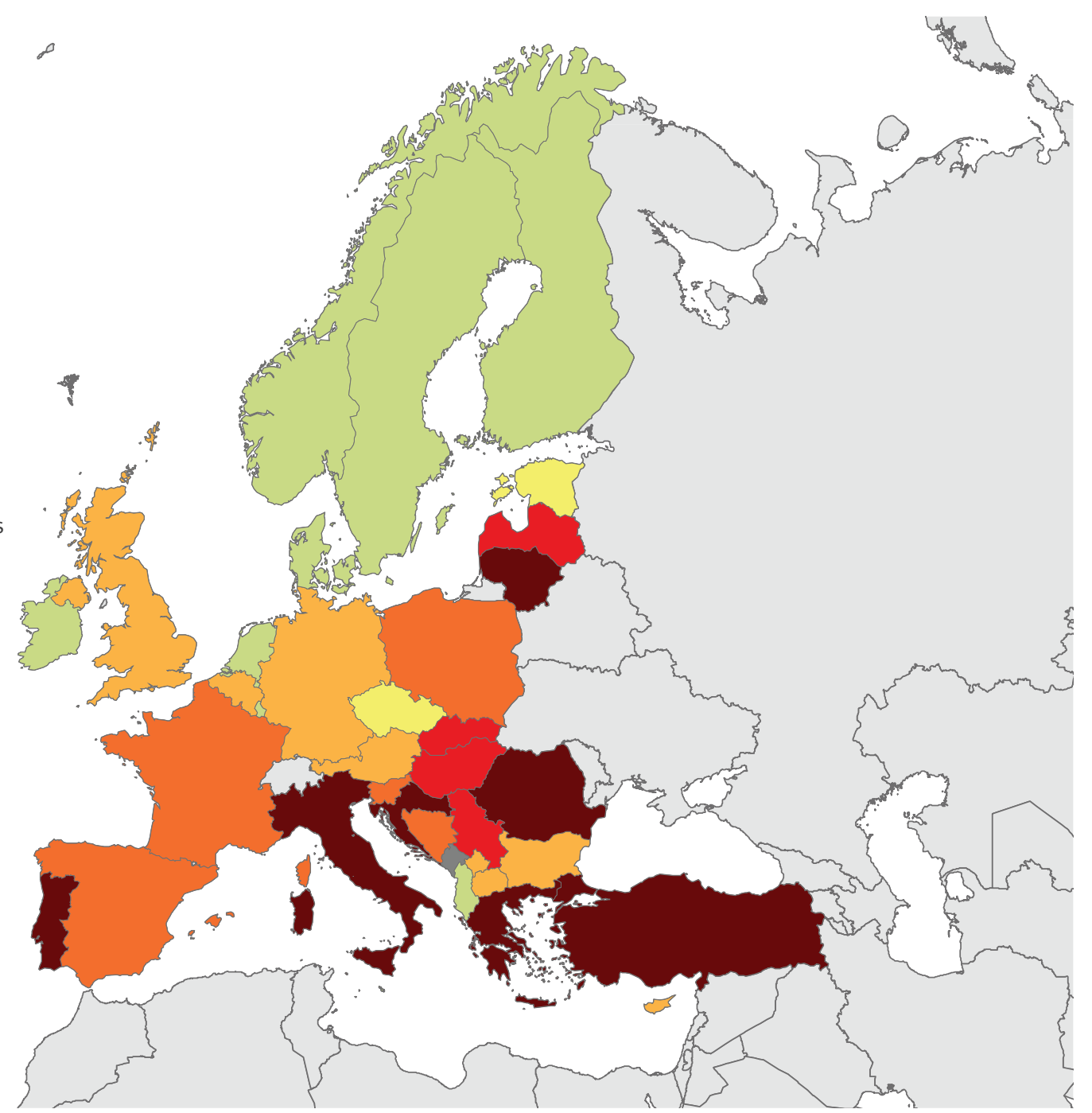

Administrative boundaries: EuroGeographics, UN-FAO.

\section{National surveillance and notification of cases as well as control guidelines}

A national system for surveillance of CRAb, either mandatory or voluntary, was in place in only 23 of the 37 countries (Table 2) with establishment of surveillance systems in only four additional countries since the previous survey, indicating that surveillance has not been further expanded and that attention and resources might have shifted away from CRAb, possibly with a focus on the spread of carbapenem-resistant Enterobacterales in many European countries [3]. Notification of cases was mandatory or recommended in 14 countries compared to nine in the period 2014 to 2015 .

Progress was made in developing national recommendations or guidelines on infection control measures for CRAb, with 15 countries having guidelines in 2019 compared to 12 countries in the 2014 to 2015 period. A national plan for containment of CRAb existed in eight countries; however, six of the seven CRAb endemic countries did not have such a plan. National guidelines on phenotypic carbapenem susceptibility testing were present in 15 countries, whereas a national guideline on molecular characterisation of carbapenem resistance was available in only three countries. Ten countries had a national screening policy or guideline. For admission screening of patients to acute care hospitals, all of these guidelines recommended selective screening in high-risk situations (outbreaks) or of highrisk groups, for example after hospitalisation abroad. The survey did not include any questions regarding the laboratory capacity and microbiological methods used for screening.

\section{National laboratory capacity}

Collection of data on isolates analysed by standardised microbiological methods is crucial for a reliable assessment of the spread of CRAb. However, laboratories with a reference function for CRAb existed in only 30 of the 37 countries. Differentiation between $A$. baumannii s.s. and other closely related species, such as $A$. pittii, $A$. 
TABLE 1

Comparison of epidemiological stages of carbapenem-resistant Acinetobacter baumannii in European countries, 2013-2019 $(\mathrm{n}=37)$

\begin{tabular}{|c|c|c|c|c|}
\hline \multirow[b]{2}{*}{ Country } & \multicolumn{3}{|c|}{ Epidemiological stage of spread of CRAb } & \multirow[b]{2}{*}{ Change between $2014-15$ and 2019} \\
\hline & $2013[2]$ & $\begin{array}{l}2014-15 \\
\text { (previously unpublished) }\end{array}$ & 2019 & \\
\hline Albania & Stage 1 & Stage 1 & Stage 1 & $\cdots$ \\
\hline Austria & Stage 1 & Stage 1 & Stage $2^{b}$ & \% \\
\hline Belgium & Stage 3 & Stage $2^{b}$ & Stage $2^{b}$ & $\cdots$ \\
\hline Bosnia and Herzegovina $^{a}$ & Stage 1 & Stage 3 & Stage 3 & $\cdots$ \\
\hline Bulgaria & Stage $2 b^{b}$ & Stage $2^{a}$ & Stage $2^{b}$ & 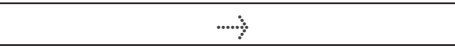 \\
\hline Croatia & Stage 5 & Stage 5 & Stage 5 & $\cdots$ \\
\hline Cyprus & Stage 3 & Stage 4 & Stage $2^{\mathrm{a}}$ & 4 \\
\hline Czechia & Stage 4 & Stage $2^{b}$ & Stage $2^{\mathrm{b}}$ & $\ldots$ \\
\hline Denmark & Stage $2^{\mathrm{b}}$ & Stage 1 & Stage 1 & $\cdots$ \\
\hline Estonia & Stage $2^{\mathrm{a}}$ & Uncertain & Stage $2^{a}$ & NA \\
\hline Finland & Stage 1 & Stage $2^{\mathrm{a}}$ & Stage 1 & 4 \\
\hline France & Stage 3 & Stage $2^{b}$ & Stage 3 & 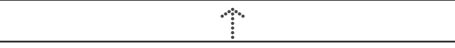 \\
\hline Germany & Stage 4 & Stage 3 & Stage $2^{b}$ & 4 \\
\hline Greece & Stage 5 & Stage 5 & Stage 5 & $\ldots$ \\
\hline Hungary & Stage 4 & Stage 4 & Stage 4 & 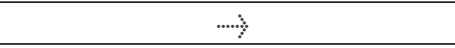 \\
\hline Iceland & Stage 0 & Stage 1 & Stage 1 & $\cdots$ \\
\hline Ireland & Stage $2 a$ & Stage 1 & Stage 1 & $\cdots$ \\
\hline Italy & Stage 5 & Stage 5 & Stage 5 & $\cdots$ \\
\hline Kosovo $^{\mathrm{b}}$ & Stage 3 & Stage 5 & Stage $2^{b}$ & 4 \\
\hline Latvia & Stage 5 & Stage $2^{b}$ & Stage 4 & \% \\
\hline Lithuania & Stage 5 & Uncertain & Stage 5 & NA \\
\hline Luxembourg & Stage 1 & Stage 0 & Stage 1 & 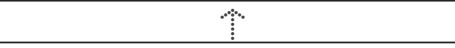 \\
\hline Malta & Stage 1 & Stage $2^{\mathrm{a}}$ & Stage 1 & 4 \\
\hline Montenegro & Stage o & Uncertain & Uncertain $^{c}$ & NA \\
\hline Netherlands & Stage 1 & Stage $2^{\mathrm{a}}$ & Stage 1 & 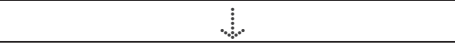 \\
\hline North Macedonia & Stage 1 & Stage 1 & Stage $2^{b}$ & 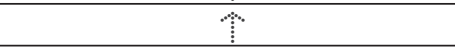 \\
\hline Norway & Stage 1 & Stage $2^{\mathrm{a}}$ & Stage 1 & 5 \\
\hline Poland & Stage $2^{\mathrm{b}}$ & Stage 4 & Stage 3 & 4 \\
\hline Portugal & Stage 4 & Stage 5 & Stage 5 & 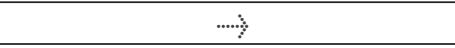 \\
\hline Romania & Stage $2^{\mathrm{b}}$ & Stage 5 & Stage 5 & $\cdots$ \\
\hline Serbia & Stage $2^{\mathrm{b}}$ & Stage 5 & Stage 4 & 4 \\
\hline Slovakia & Stage 4 & Stage 4 & Stage 4 & $\cdots$ \\
\hline Slovenia & Stage $2^{a}$ & Stage 4 & Stage 3 & 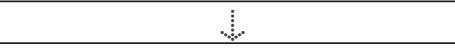 \\
\hline Spain & Stage 3 & Stage 4 & Stage 3 & 4 \\
\hline Sweden & Stage $2^{\mathrm{a}}$ & Stage $2^{\mathrm{a}}$ & Stage 1 & 4 \\
\hline Turkey & Stage $2^{\mathrm{b}}$ & Stage 5 & Stage 5 & $\ldots$ \\
\hline United Kingdom $^{d}$ & Stage 4 & Stage 4 & Stage $2^{b}$ & 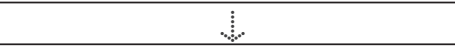 \\
\hline
\end{tabular}

CRAb: carbapenem-resistant Acinetobacter baumannii. NA: not applicable.

The epidemiological stages of carbapenem-resistant Acinetobacter baumannii are defined as follow: stage o: no cases reported; stage 1: sporadic occurrence (epidemiologically-unrelated single cases); stage 2a: single hospital outbreak (two or more epidemiologicallyassociated cases with indistinguishable geno- or phenotype in a single institution); stage 2b: sporadic hospital outbreaks (unrelated hospital outbreaks with epidemiologically unrelated introduction or different strains, no autochthonous inter-institutional transmission reported); stage 3: regional spread (more than one epidemiologically-related hospital outbreak confined to hospitals that are part of the same region or health district, indicating regional autochthonous inter-institutional transmission); stage 4: inter-regional spread (multiple epidemiologically-related outbreaks occurring in different health districts, indicating inter-regional autochthonous inter-institutional transmission); stage 5: endemic situation (most hospitals in a country are repeatedly seeing cases admitted from autochthonous sources).

${ }^{a}$ The results reported for Bosnia and Herzegovina only apply to the Republic of Srpska.

${ }^{b}$ This designation is without prejudice to positions on status, and is in line with United Nations Security Council resolution 1244/99 and the International Court of Justice Opinion on the Kosovo declaration of independence.

c Acinetobacter spp. and Pseudomonas spp. are becoming a major problem in Montenegro as they are frequently isolated and are increasingly resistant to carbapenems. However, a National Reference Laboratory for these bacteria does not exist and all answers in the manuscript are connected with that fact. Therefore, it was judged that a realistic picture of the situation cannot be presented.

${ }^{d}$ The reported results are for the United Kingdom overall. The epidemiological stages vary among countries within the United Kingdom. 


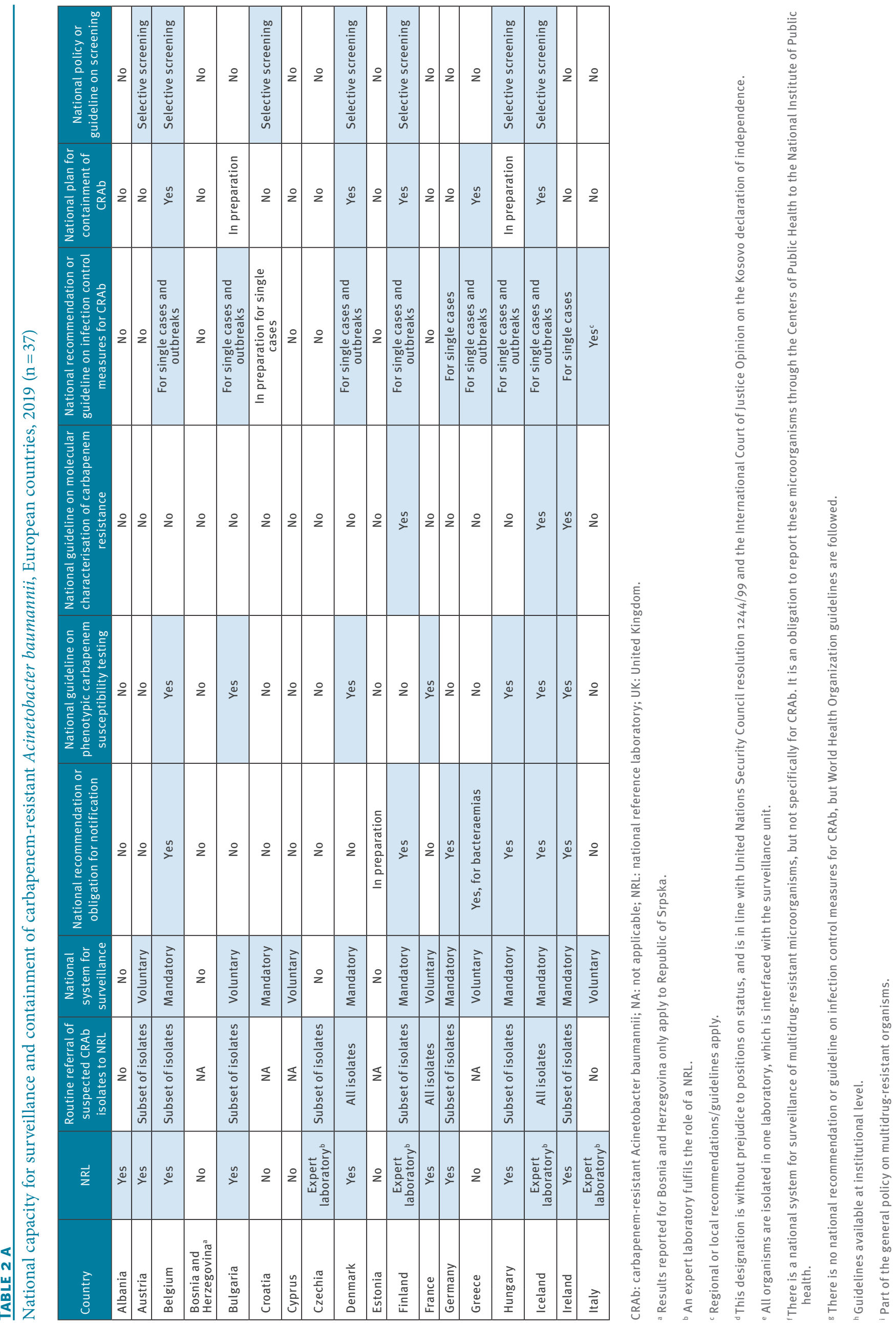




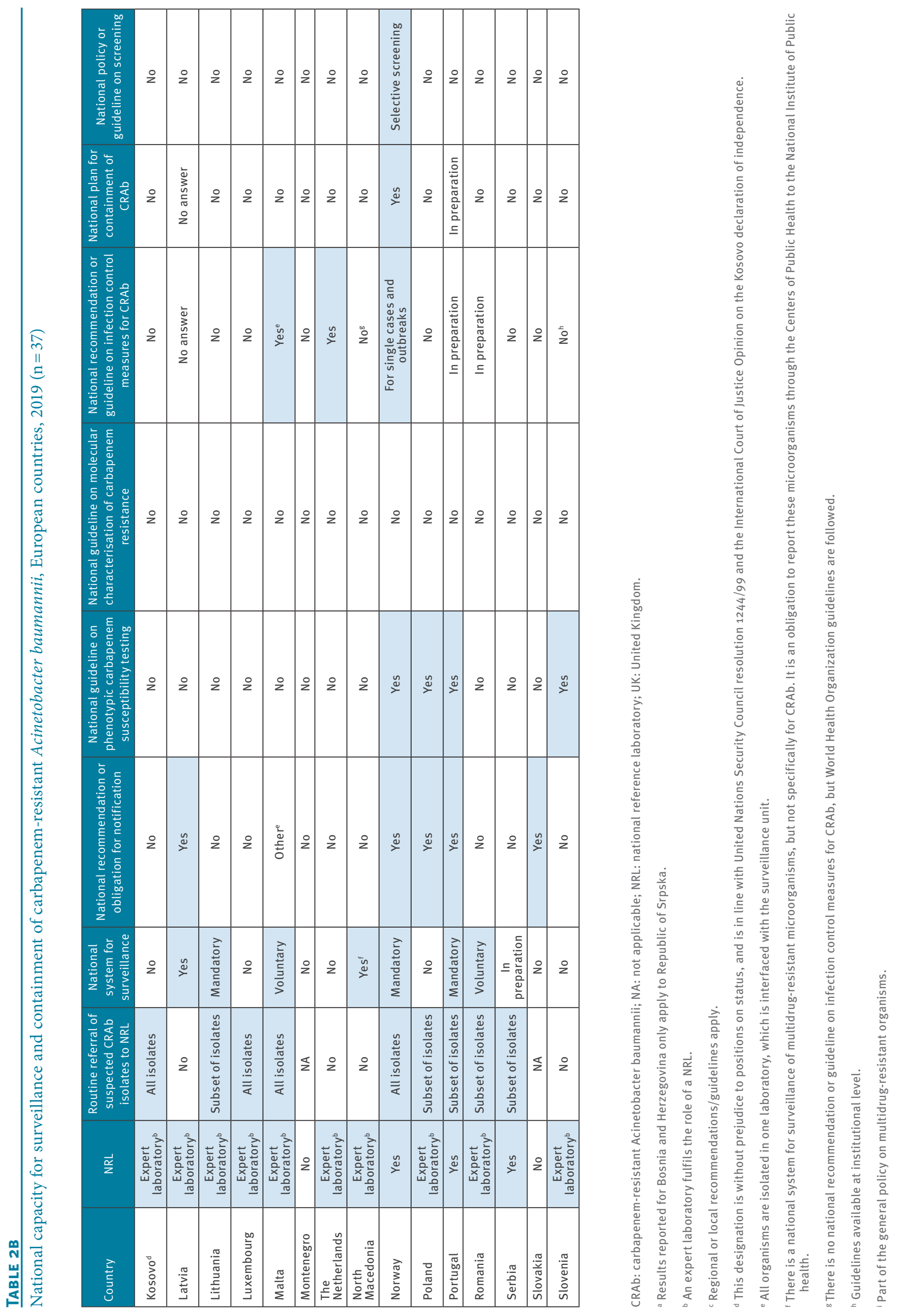




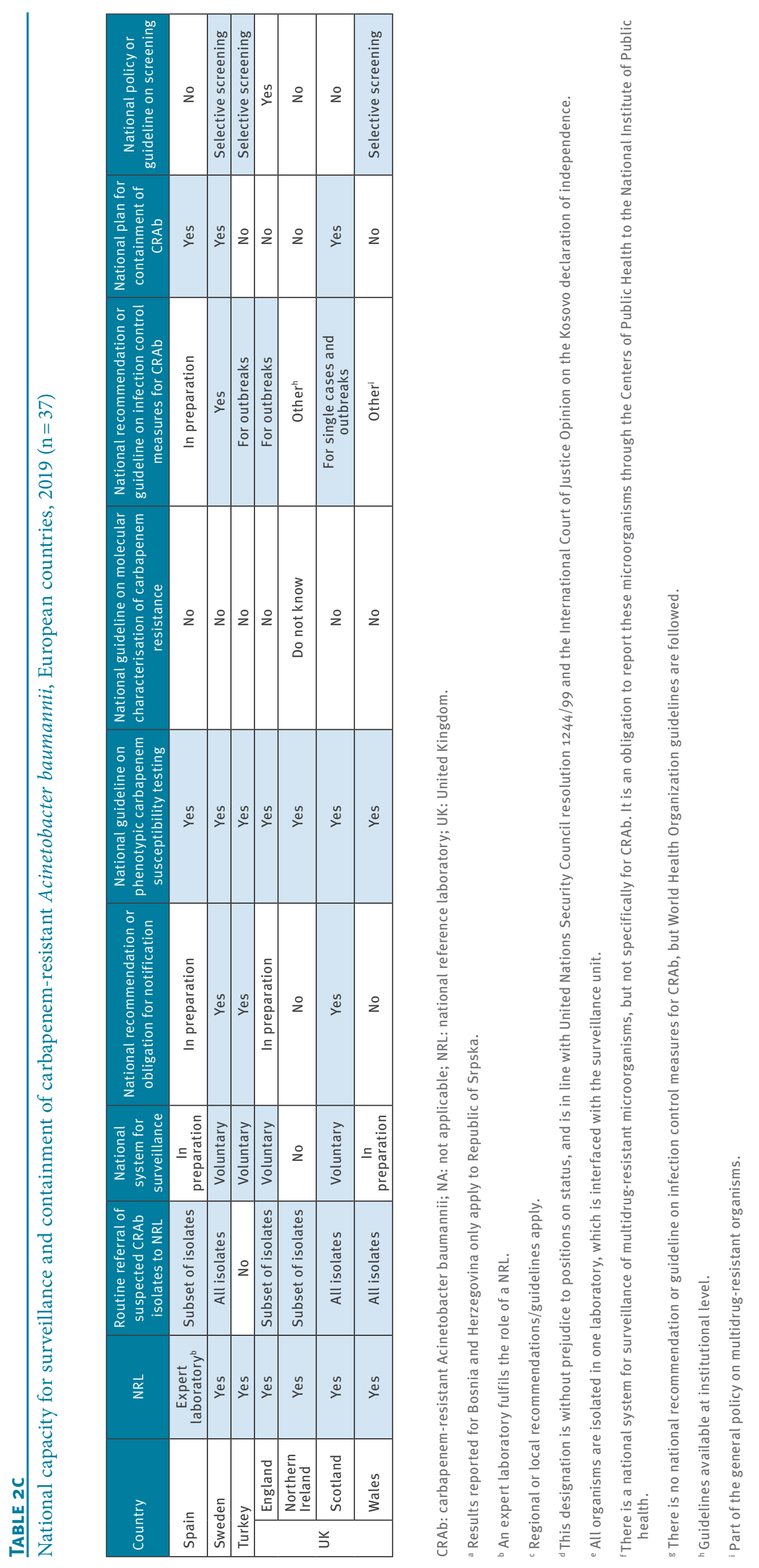




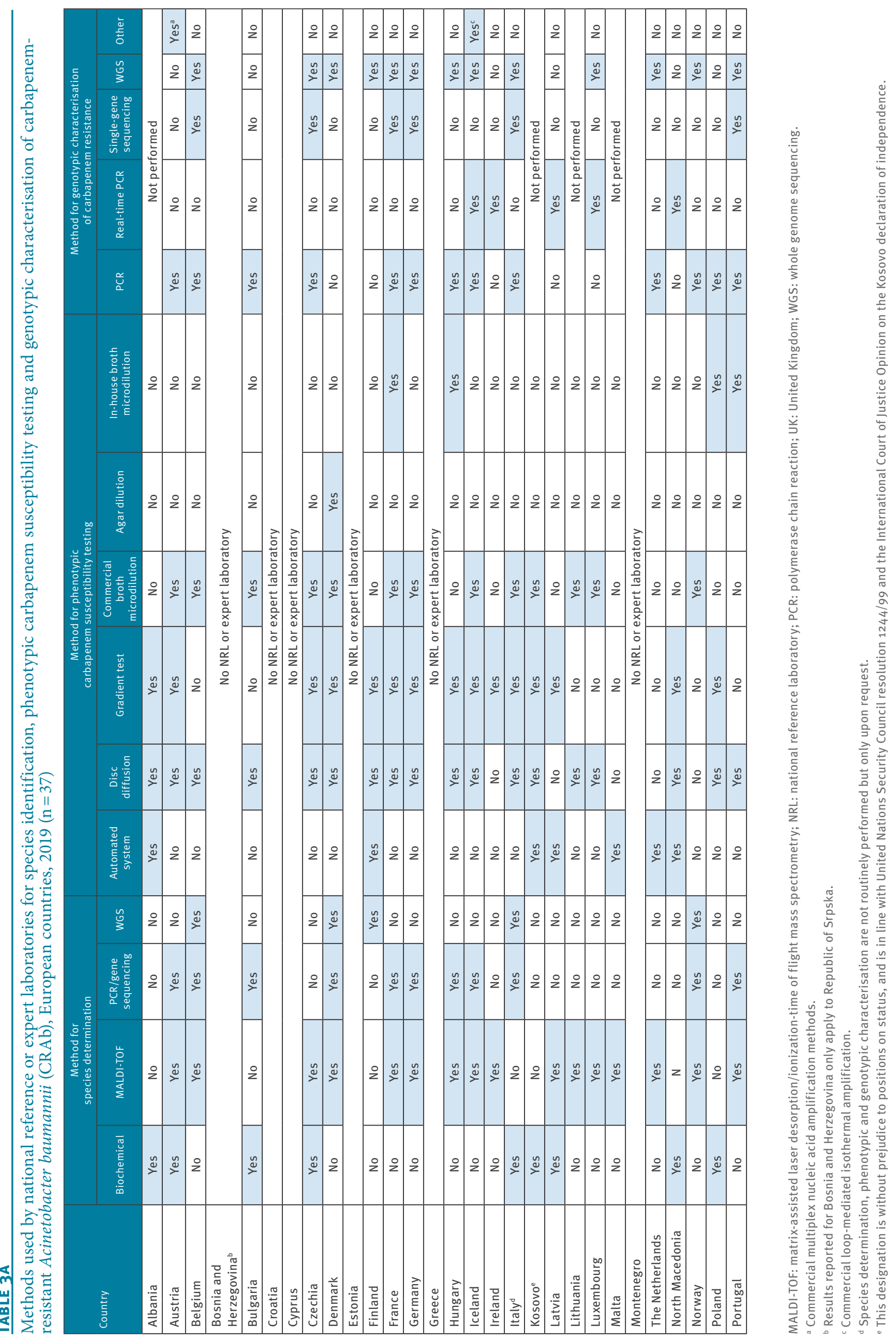




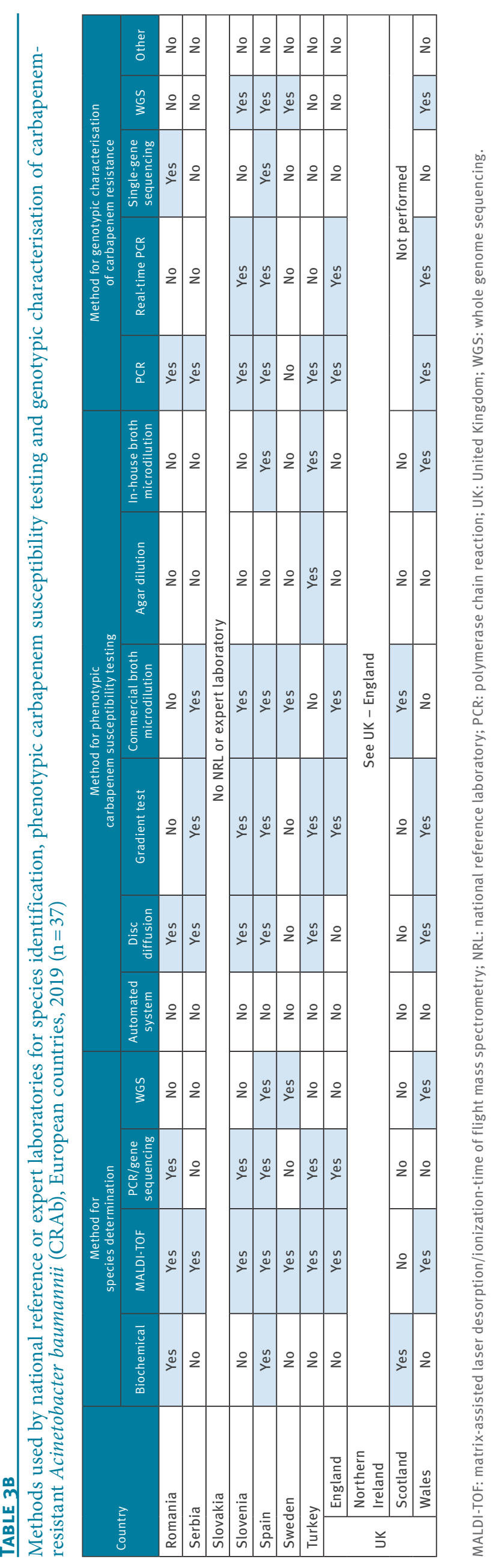


nosocomialis, $A$. dijkshoorniae or $A$. seifertii, has been considered difficult in the past, but has improved with the widespread availability of matrix-assisted laser desorption/ionization-time of flight mass spectrometry (MALDI-TOF/MS) method for species discrimination [4]. Widespread use of this technology in clinical laboratories is reflected in the answers indicating that, in 11 countries, all or nearly all clinical laboratories routinely use MALDI-TOF/MS for species identification; however, on the other end of the scale, experts from 13 countries reported that no or very few clinical laboratories in their country have access to MALDI-TOF/MS. In the national reference or expert laboratories, the most common method for species identification was MALDI-TOF/MS $(n=22)$ followed by PCR / gene-sequencing $(n=15)$.

The most frequently used methods for determination of phenotypic carbapenem susceptibility were disk diffusion $(n=23)$, gradient tests $(n=19)$ and commercial broth microdilution $(n=17)$. European Committee on Antimicrobial Susceptibility Testing (EUCAST) breakpoints for susceptibility testing were used in all countries with a laboratory with reference function. Most national reference or expert laboratories (25 of 30 laboratories) reported that they perform genotypic characterisation of carbapenem resistance. The most commonly used methods were PCR $(n=18)$ and whole genome sequencing $(n=16)$.

Colistin susceptibility testing of $A$. baumannii isolates was performed in 25 of the 30 reference or expert laboratories with broth microdilution according to EUCAST recommendations (four laboratories did not use broth microdilution and the information was missing for one laboratory). Of the 25 laboratories using broth microdilution for colistin testing, nine tested all referred $A$. baumannii isolates for colistin susceptibility and the remaining 16 only tested a subset of isolates. The survey did not include questions regarding internal and external quality assessment in the laboratories. Detailed information on the laboratory capacity is provided in Table 3 .

\section{Ethical statement}

This study did not involve personal data and ethical approval was thus not required. The release of the included national data was approved by the authors.

\section{Discussion}

CRAb poses a significant threat to patients and healthcare systems in countries of the European Union (EU)/ European Economic Area (EEA) [5] with an estimated 2,363 annual attributable deaths in 2015 [6]. According to 2018 data from the European Antimicrobial Resistance Surveillance Network (EARS-Net), nearly a third of invasive Acinetobacter spp. isolates in the EU/EEA are already resistant to carbapenems, limiting the availability of adequate treatment [7]. Several reports on outbreaks of CRAb in European countries have recently been published, possibly indicating increasing spread [8-12]. These outbreaks frequently affect intensive care units, and morbidity and mortality are high. In the current study however, our results show that perception of the epidemiological situation of CRAb has not changed substantially since the last survey conducted in 2015. The extent of spread of CRAb appeared to be decreasing in some countries while it was increasing in other countries. The underlying reasons for these developments are not clear. On the one hand, decreasing epidemiological stages may reflect successful local or national control efforts. Control programmes were shown to be effective both in settings of high endemicity [13] and outbreaks $[14,15]$. On the other hand, the decrease in the epidemiological stage was not always confirmed by the carbapenem resistance rates in invasive isolates reported by EARS-Net or the Central Asian and European Surveillance of Antimicrobial Resistance network (CAESAR) [7,16]. Some countries reported a low epidemiological stage of spread of CRAb whereas EARS-Net showed that, in 2018 , a high or very high proportion of Acinetobacter spp. invasive isolates in the same country were resistant to carbapenems [7]. One possible explanation for such discrepancies could be that local outbreaks of CRAb are driving the national resistance proportions in Acinetobacter spp. invasive isolates as reported to EARS-Net. In addition, two countries also mentioned increasing numbers of carbapenem-resistant isolates in Acinetobacter species other than $A$. baumannii s.s., e.g. A. pittii or $A$. Iwoffii that were not included in this assessment of epidemiological stages but are included in the EARSNet collection of data on Acinetobacter species. Finally, the epidemiological stages were determined by a self-assessment of the national representatives and might have been affected by unavailability of national surveillance data or reference laboratories in some countries, especially as differentiation between stages might be difficult without molecular typing results. The three surveys over time were also not always answered by the same national expert and it cannot be excluded that changes resulted from differences in subjective judgement.

An interest to participate in a European structured survey including the collection of CRAb isolates or whole genome sequencing data thereof as well as related epidemiological information was expressed by 32 countries. Such a survey would help identify successful clones and predominant lineages and the extent of their spread, provide a better understanding of predominant resistance mechanisms to carbapenems and other antimicrobials and allow conclusions on potential cross-border spread of CRAb.

EURGen-Net carbapenem-resistant Acinetobacter baumannii capacity survey group

Austria: Petra Apfalter and Rainer Hartl; Belgium: Te-Din Daniel Huang and Olivier Denis; Bulgaria: Stefana Sabtcheva and Ivan N. Ivanov; Croatia: Arjana Tambić Andrašević and Irina Pristaš; Cyprus: Panagiota Maikanti and Despo Pieridou; Czechia: Jaroslav Hrabak and Helena Žemličková; Denmark: Anette M. Hammerum and Louise Roer; Estonia: 
Marika Jürna-Ellam; Finland: Jari Jalava and Kati Räisänen; France: Anaïs Potron and Patrick Plésiat; Germany: Niels Pfennigwerth; Greece: Spyros Pournaras and Alkiviadis Vatopoulos, Hungary: Ákos Tóth and Andrea Kurcz; Iceland: Kristján Orri Helgason; Ireland: Karen Burns; Italy: Monica Monaco and Giulia Errico; Latvia: Oksana Savicka; Lithuania: Aistė Mierauskaitė; Luxembourg: Monique Perrin and Alexandre Mzabi; Malta: Elizabeth Anne Scicluna and Nina Nestorova; Netherlands: Leo M. Schouls; Norway: Ørjan Samuelsen and Oliver Kacelnik; Poland: Dorota Żabicka; Portugal: Manuela Caniça and Vera Manageiro; Romania: Irina Codita and Gabriel Popescu; Slovakia: Eva Schréterová and Andrea Žáková; Slovenia: Mateja Pirš; Spain: Jesús OteoIglesias and Belén Aracil; Sweden: Karin Sjöström and Petra Edquist; United Kingdom (UK)-England: Katie L. Hopkins and Jane Turton, UK- Northern Ireland: Christopher Nugent; UK Scotland: Alistair Leanord; UK-Wales: Mandy Wootton and Mari Morgan; Albania: Andi Koraqi and Artan Bego; Bosnia and Herzegovina: Maja Travar; Kosovoa: Arsim Kurti and Lul Raka; Montenegro: Vineta Vuksanović and Milena Lopičić ; North Macedonia: Ana Kaftandjieva; Serbia: Ivana Ćirković and Deana Medic; Turkey: Serap Süzük Yildiz and Hüsniye Şimşek.

a This designation is without prejudice to positions on status, and is in line with United Nations Security Council Resolution $1244 / 99$ and the International Court of Justice Opinion on the Kosovo declaration of independence.

\section{Conflict of interest}

KLH and JT are members of PHE's Antimicrobial Resistance and Healthcare Associated Infections Reference Unit, which has received financial support for conference attendance, lectures, research projects, or contracted evaluations from numerous sources, including Accelerate Diagnostics, Achaogen Inc, Allecra Therapeutics, Amplex, AstraZeneca UK Ltd, AusDiagnostics, Basilea Pharmaceutica, Becton Dickinson Diagnostics, bioMérieux, Bio-Rad Laboratories, British Society for Antimicrobial Chemotherapy, Cepheid, Check-Points B.V., Cubist Pharmaceuticals, Department of Health, Enigma Diagnostics, the European Centre for Disease Prevention and Control, Food Standards Agency, GenePOC, GlaxoSmithKline Services Ltd, Helperby Therapeutics, Henry Stewart Talks, International Health Management Associates Ltd, Innovate UK, Kalidex Pharmaceuticals, Melinta Therapeutics, Merck Sharpe and Dohme, Meiji Seika Pharma Co Ltd, Mobidiag, Momentum Biosciences Ltd, Neem Biotech, NIHR, Nordic Pharma Ltd, Norgine Pharmaceuticals, Paratek, Rabiotics Rx, Rempex Pharmaceuticals Ltd, Roche, Rokitan Ltd, Smith and Nephew UK Ltd, Shionogi and Co Ltd, Tetraphase Pharmaceuticals, Trius Therapeutics, VenatoRx Pharmaceuticals, Wockhardt Ltd, and the World Health Organization.

\section{Authors' contributions}

F. Lötsch, B. Albiger, D.L. Monnet, M. Struelens, A. Kohlenberg: design and implementation of the survey, compilation of information received from individual countries and preparation of European overview, drafting and reviewing the manuscript;

\section{H. Seifert: design of the survey and review of the manuscript;}

EURGen-Net carbapenem-resistant Acinetobacter baumannii capacity survey group: compilation and analysis of national data from laboratories and surveillance databases, validation of national data included in the manuscript and review of the manuscript.

\section{References}

1. Peleg AY, Seifert H, Paterson DL. Acinetobacter baumannii: emergence of a successful pathogen. Clin Microbiol Rev. 2008;21(3):538-82. https://doi.org/10.1128/CMR.00058-07 PMID: 18625687

2. European Centre for Disease Prevention and Control (ECDC). Carbapenemase-producing bacteria in Europe - Interim results from the European survey on carbapenemase-producing Enterobacteriaceae (EuSCAPE) project 2013. Stockholm: ECDC; 2013. Available from: https://ecdc.europa.eu/sites/portal/ files/media/en/publications/Publications/antimicrobialresistance-carbapenemase-producing-bacteria-europe.pdf

3. Brolund A, Lagerqvist N, Byfors S, Struelens MJ, Monnet $\mathrm{DL}$, Albiger B, et al. . Worsening epidemiological situation of carbapenemase-producing Enterobacteriaceae in Europe, assessment by national experts from 37 countries, July 2018. Euro Surveill. 2019;24(9):1900123. https://doi. org/10.2807/1560-7917.ES.2019.24.9.1900123 PMID: 30862330

4. Marí-Almirall M, Cosgaya C, Higgins PG, Van Assche A, Telli M, Huys G, et al. MALDI-TOF/MS identification of species from the Acinetobacter baumannii (Ab) group revisited: inclusion of the novel A. seifertii and A. dijkshoorniae species. Clin Microbiol Infect. 2017;23(3):210.e1-9. https://doi.org/10.1016/j. cmi.2016.11.020 PMID: 27919649

5. European Centre for Disease Prevention and Control (ECDC). Rapid risk assessment: Carbapenem-resistant Acinetobacter baumannii in healthcare settings. Stockholm: ECDC; 2016. Available from: https://www.ecdc.europa.eu/sites/default/ files/media/en/publications/Publications/8-Dec-2016-RRAAcinetobacter\%2obaumannii-Europe.pdf

6. Cassini A, Högberg LD, Plachouras D, Quattrocchi A, Hoxha A, Simonsen GS, et al. , Burden of AMR Collaborative Group. Attributable deaths and disability-adjusted life-years caused by infections with antibiotic-resistant bacteria in the EU and the European Economic Area in 2015: a populationlevel modelling analysis. Lancet Infect Dis. 2019;19(1):5666. https://doi.org/10.1016/S1473-3099(18)30605-4 PMID: 30409683

7. European Centre for Disease Prevention and Control (ECDC). Surveillance of antimicrobial resistance in Europe 2018. Annual Report of the European Antimicrobial Resistance Surveillance Network (EARS-Net). Stockholm: ECDC; 2019. Available from: https://www.ecdc.europa.eu/sites/default/files/documents/ surveillance-antimicrobial-resistance-Europe-2018.pdf

8. Strateva T, Sirakov I, Stoeva T, Stratev A, Dimov S, Savov E, et al. Carbapenem-resistant Acinetobacter baumannii: Current status of the problem in four Bulgarian university hospitals (2014-2016). J Glob Antimicrob Resist. 2019;16:266-73. https:// doi.org/10.1016/j.jgar.2018.10.027 PMID: 30412782

9. Munier AL, Biard L, Legrand M, Rousseau C, Lafaurie M, Donay $\mathrm{JL}$, et al. Incidence, risk factors and outcome of multi-drug resistant Acinetobacter baumannii nosocomial infections during an outbreak in a burn unit. Int J Infect Dis. 2019;79:17984. https://doi.org/10.1016/j.ijid.2018.11.371 PMID: 30529108

10. Venditti C, Vulcano A, D’Arezzo S, Gruber CEM, Selleri $M$, Antonini $M$, et al. Epidemiological investigation of an Acinetobacter baumannii outbreak using core genome multilocus sequence typing. J Glob Antimicrob Resist. 2019;17:245-9. https://doi.org/10.1016/j.jgar.2018.11.027 PMID: 30553929

11. Potron A, Bour M, Triponney P, Muller J, Koebel C, A. Bonnin R, et al. Sequential emergence of colistin and rifampicin resistance in an OXA-72-producing outbreak strain of Acinetobacter baumannii. Int J Antimicrob Agents. 2019;53(5):669-73. https://doi.org/10.1016/j. ijantimicag.2019.01.012 PMID: 30685310

12. Eigenbrod T, Reuter S, Gross A, Kocer K, Günther F, Zimmermann S, et al. Molecular characterization of carbapenem-resistant Acinetobacter baumannii using WGS revealed missed transmission events in Germany from 2012-15. J Antimicrob Chemother. 2019;74(12):3473-80, https://doi. org/10.1093/jac/dkz36o PMID: 31504593

13. Valencia-Martín R, Gonzalez-Galan V, Alvarez-Marín R, Cazalla-Foncueva AM, Aldabó T, Gil-Navarro MV, et al., In representation of A. baumannii eradication program. A multimodal intervention program to control a long-term Acinetobacter baumannii endemic in a tertiary care hospital. Antimicrob Resist Infect Control. 2019;8(1):199. https://doi. org/10.1186/s13756-019-0658-4 PMID: 31827780

14. Metan G, Zarakolu P, Otlu B, Tekin I, Aytac H, Bolek EC, et al. Emergence of colistin and carbapenem-resistant Acinetobacter calcoaceticus-Acinetobacter baumannii (CCR-Acb) complex in a neurological intensive care unit followed by successful control of the outbreak. J Infect Public Health. 2020;13(4):564-70. https://doi.org/10.1016/j.jiph.2019.09.013 PMID: 31672426 
15. Molter G, Seifert H, Mandraka F, Kasper G, Weidmann B, Hornei $B$, et al. Outbreak of carbapenem-resistant Acinetobacter baumannii in the intensive care unit: a multi-level strategic management approach. J Hosp Infect. 2016;92(2):194-8. https://doi.org/10.1016/j.jhin.2015.11.007 PMID: 26778130

16. World Health Organization Regional Office for Europe (WHO/ Europe). Central Asian and Eastern European Surveillance of Antimicrobial Resistance, Annual Report for 2019. Copenhagen: WHO/Europe; 2019. Available from: http://www.euro.who.

int/__data/assets/pdf_file/0003/418863/53373-WHO-CAESARannual-report-2019.pdf

\section{License, supplementary material and copyright}

This is an open-access article distributed under the terms of the Creative Commons Attribution (CC BY 4.0) Licence. You may share and adapt the material, but must give appropriate credit to the source, provide a link to the licence and indicate if changes were made.

Any supplementary material referenced in the article can be found in the online version.

This article is copyright of the authors or their affiliated institutions, 2020. 